\section{INFLUENCE OF VEIN VALVES IN THE DEVELOPMENT OF ARTERIOSCLEROSIS IN VENOARTERIAL GRAFTS IN THE RABBIT}

Coronary saphenous vein grafts in human beings have a more limited long-term patency rate than internal thoracic artery grafts, primarily because of more rapid development of arteriosclerosis. The factors responsible for this increased susceptibility are not completely understood. To test the hypothesis that vein valves may influence this process, we studied 48 hypercholesterolemic rabbits with jugular vein grafts interposed into the carotid arterial circulation. In 24 animals (group A), the vein segments did not contain a vein valve. In the other 24 animals (group B), a vein valve was present. Both groups were further divided in four subgroups of six to be put to death at $2,4,6$, and 8 weeks after the operation. All animals were fed a $2 \%$ cholesterol diet. At postmortem examination, alternate $2 \mathrm{~mm}$ sections were either stained with hematoxylin and eosin for histologic and morphometric studies or frozen in liquid nitrogen for immunohistochemistry and in situ hybridization studies. Proliferating cell nuclear antigen immunostaining was used to study cell proliferation. Wall thickness of vein grafts increased with time. During the first 2 weeks intimal and medial thickening was primarily due to an increase in numbers of cells. Between 2 and 6 weeks further intimal and medial thickening occurred, but without additional increase in cell numbers. After 6 weeks, foam cells and lipid deposits started to appear. By 8 weeks, changes identical to those seen in arteriosclerotic plaques in human beings were evident. These changes developed sooner and with more intensity in group $B$ animals $(p<0.01$ to 0.001 ), and they developed faster and with more severity in segments of vein located distal to the valve than in the segments located proximal to the valve $(p<$ 0.001). This is the first controlled experiment demonstrating that the presence of valves in the vein segments is associated with augmented and accelerated intimal changes leading to vein atheromatosis. (J THORAC CARDIOVASC SURG 1995;110:1381-90)

Aurelio Chaux, $\mathrm{MD}^{\mathrm{a}}$ (by invitation), Xin Min Ruan, $\mathrm{MD}^{\mathrm{a}}$ (by invitation), Michael C. Fishbein, MD $^{\mathrm{b}}$ (by invitation), Meenu Sandhu, $\mathrm{MS}^{\mathrm{e}}$

(by invitation), and Jack M. Matloff, MD, ${ }^{a}$ Los Angeles, Calif.
T he reported patency rate of human saphenous vein grafts is variable, but it is generally accepted that the rate is about $80 \%$ to $90 \%$ at 1 year and $50 \%$ to $70 \%$ at 7 to 10 years. ${ }^{1,2}$ The changes leading to vein graft occlusion in human beings have been

From the Departments of Cardiothoracic Surgery, ${ }^{a}$ Pathology, and Statistical Computing and Clinical Services, ${ }^{\circ}$ Cedars-Sinai Medical Center, Los Angeles, Calif.

This project was funded in part by the Western Cardiac Foundation and the Ahmanson Foundation.

Read at the Seventy-fifth Annual Meeting of The American Association for Thoracic Surgery, Boston, Mass., April 23-26, 1995.

Address for reprints: Aurelio Chaux, MD, Co-Chairman, Department of Cardiothoracic Surgery, 8700 Beverly Blvd., Suite 6215, Los Angeles, CA 90048. classified as acute ( $<1$ month), subacute ( 1 to 2 months), intermediate (1 to 5 years), and long term ( $>5$ years). ${ }^{3}$ The acute and subacute changes are attributed to thrombosis or intimal thickening. Intermediate and long-term changes are due to development of arteriosclerosis-like lesions. Intimal changes in experimental venoarterial graft models, including the effect of hyperlipidemia, have been studied in the rabbit, ${ }^{4}$ as well as in dogs and rhesus monkeys. ${ }^{5-8}$ The contribution of vein valves to the development of these changes has been suspected for some time. ${ }^{9-12}$ This series of experiments was designed to study, in a controlled fashion, the pos- 
Table I. Distribution of the 48 New Zealand White rabbits

\begin{tabular}{ccc}
\hline $\begin{array}{c}\text { Group A (No.): } \\
\text { No valve present }\end{array}$ & $\begin{array}{c}\text { Group B }(\text { No. }): \\
\text { Valve present }\end{array}$ & $\begin{array}{c}\text { Postmontem exam } \\
\text { time }(w k)\end{array}$ \\
\hline 6 & 6 & 2 \\
6 & 6 & 4 \\
6 & 6 & 6 \\
$\frac{6}{24}$ & $\frac{6}{24}$ & 8 \\
\hline
\end{tabular}

sible effect of vein valves on vascular wall thickening and subsequent atheromatous vein graft changes in a model of accelerated arteriosclerosis in the rabbit.

\section{Methods}

Animal model. The rabbits in this study were fed a diet containing $2 \%$ cholesterol, starting 1 week before the operation and continuing throughout the experiment. To determine the possible effect of vein valves on the development of intimal thickening and on the formation of arteriosclerosis-like lesions, we implanted autologous jugular vein grafts into the common carotid artery of $48 \mathrm{New}$ Zealand White rabbits with weights between 3 and $3.5 \mathrm{~kg}$. In 24 animals (group A), a segment of the jugular vein that did not contain a valve was used. In another 24 rabbits (group B), the segment of vein contained a vein valve, which is consistently found in the rabbit at the junction between the external and internal jugular veins. This valve can be easily identified by visual inspection and injection of heparinized saline solution in the direction opposite the blood flow. All animals were anesthetized with a $4 \mathrm{mg} / \mathrm{kg}$ concentration of ketamine and a $2 \mathrm{mg} / \mathrm{kg}$ concentration of xylazine mixed in a bolus injection. A drip of $200 \mathrm{mg}$ of ketamine and $40 \mathrm{mg}$ of xylazine in $250 \mathrm{ml}$ of normal saline solution was used for maintenance of anesthesia.

The external and internal jugular veins were exposed on one side of the neck after systemic heparinization $(3 \mathrm{mg} / \mathrm{kg}$ ). The vein was removed and flushed with heparinized saline solution (10 mg in $1000 \mathrm{ml}$ normal saline solution). The vein that had been marked for orientation was reversed at the time of implantation. The carotid artery was exposed and clamped proximally and distally. With the use of surgical magnification and continuous 8-0 polypropylene sutures, end-to-side anastomoses were performed distally and proximally. The carotid artery was tied close to both anastomoses and divided in between. The average length of the grafts was $2 \mathrm{~cm}$. Animal care complied with the "Guide for the Care and Use of Laboratory Animals" prepared by the Institute of Laboratory Animal Resources and published by the National Institutes of Health (NIH Publication No. 86-23, revised 1985).

Groups A and B were each further subdivided into four groups of six animals and killed at 2-week intervals (Table I). To obtain the desired number of animals in each group, we had to operate on a total of 63 rabbits. Fifteen could not be used, 12 because they had clotted grafts at postmortem examination (19\% occlusion rate) and three
Table II. Immunochemistry protocol

\begin{tabular}{ccc}
\hline Antiserum & \multicolumn{1}{c}{ Specificity } & Dilution \\
\hline $\begin{array}{l}\text { Monoclonal mouse } \\
\text { antihuman } \alpha \text {-smooth }\end{array}$ & Smooth muscle & $1: 50$ \\
$\begin{array}{l}\text { muscle actin } \\
\text { Monoclonal mouse } \\
\text { antihuman macro- } \\
\text { phage, CD68 }\end{array}$ & Macrophages & $1: 100$ \\
$\begin{array}{c}\text { Anti-PCNA/cyclin } \\
\text { mouse monoclonal } \\
\text { antibody lgG } 24\end{array}$ & Proliferating cells & $1: 80$ \\
\hline
\end{tabular}

IgG, Immunoglobulin G.

because of problems with tissue processing. Occlusion rate was due to surgical technical mistakes during the learning curve; graft occlusions occurred rarely thereafter. Additionally, six other animals were operated on for the purpose of studying the very early changes that occur in the vein wall; three were put to death at 3 days and three at 7 days. These six animals constitute a separate group in which the quantitative morphometric studies were not carried out, and only histologic and immunohistochemical studies were performed. Before being killed, the animals were anesthetized as described earlier; the grafts were dissected from the surrounding tissues and removed together with segments of carotid artery attached proximally and distally. After being flushed with heparinized saline solution, the distal end of the artery was tied and the graft distended with $4 \%$ paraformaldehyde until the diameter was approximately the same as in vivo. The proximal end of the artery was then tied, and the specimen was immersed in $4 \%$ paraformaldehyde solution for 1 hour. The tissue was then washed with a solution of $15 \%$ sucrose and immersed in the same solution for 12 hours. Next, $2 \mathrm{~mm}$ cross sections were obtained, and alternate sections were either further fixed in $10 \%$ formalin for morphologic analysis or immediately frozen in O.C.T. compound (Miles, Inc., Elkhart, Ind.) and dry ice for storage at $-70 \mathrm{C}$ to be used for immunohistochemical and in situ hybridization studies.

The immunohistochemical studies were performed with commercially available antisera and a standard Avidin-Biotin LS AB 2 kit (Dak Laboratories, Carpenteria, Calif.). Table II shows the antisera, their specificity, and the dilutions used. For negative control studies, the primary antisera were deleted from the procedure. Positive controls consisted of tissue known to contain the target antigens (human intestine and tonsil).

Morphometry. The normal structure of the jugular vein in the New Zealand White rabbit consists of a single layer of endothelial cells, a very narrow medial layer formed mainly by smooth muscle cells, and a wider adventitial layer formed mainly of collagen with few scattered smooth muscle cells. The internal elastic lamina is scattered and difficult to identify consistently. Given these facts, we decided, for the purpose of these studies, to make all the measurements of wall area and wall thickness from the lumen to the limit between media and adventitia. This 
Table III. Comparison of mean thickness/area between group $A(n=24)$ and group $B(n=24)$

\begin{tabular}{|c|c|c|c|c|c|c|}
\hline \multirow[b]{2}{*}{ Weeks } & \multicolumn{3}{|c|}{ Wall thickness $(\mu \mathrm{m})$} & \multicolumn{3}{|c|}{ Wall area $(\mu \mathrm{m} / \mathrm{mm})$} \\
\hline & $\begin{array}{c}\text { Group } A \\
(\text { mean } \pm S E M)\end{array}$ & $\begin{array}{c}\text { Group B } \\
\text { (mean } \pm S E M)\end{array}$ & $\begin{array}{c}p \\
\text { Value }\end{array}$ & $\begin{array}{c}\text { Group } A \\
(\text { mean } \pm S E M)\end{array}$ & $\begin{array}{c}\text { Group B } \\
\text { (mean } \pm S E M)\end{array}$ & $\begin{array}{c}p \\
\text { Value }\end{array}$ \\
\hline 2 & $70.3 \pm 5.6$ & $96.5 \pm 8.3$ & NS & $72.8 \pm 5.3$ & $95.5 \pm 6.3$ & NS \\
\hline 4 & $128.9 \pm 14.1$ & $183.0 \pm 19.7$ & $<0.01$ & $127.1 \pm 13.8$ & $183.4 \pm 21.6$ & $<0.006$ \\
\hline 6 & $165.7 \pm 7.1$ & $257.3 \pm 11.6$ & $<0.001$ & $166.7 \pm 5.8$ & $255.4 \pm 14.4$ & $<0.001$ \\
\hline 8 & $202.5 \pm 17.9$ & $266.5 \pm 14.4$ & $<0.01$ & $202.9 \pm 16.2$ & $266.9 \pm 12.6$ & $<0.01$ \\
\hline
\end{tabular}

SEM, Standard error of the mean; $N S$, not significant.

limit was consistently clear and easy to identify. Mean wall thickness was determined by taking measurements in micrometers at four equidistant sites, 90 degrees from each other, around the vessel perimeter. Mean area was defined as the total area encompassed within the vessel wall (excluding the adventitia) minus the luminal area; the units of measurement were micrometer squared.

Measurements of intimal and medial thickness, luminal and intimal circumference, and intimal area were obtained with a calibrated, computer-based, image-measuring software system (Optimas, BioScan, Inc., Edmonds, Wash.), on magnified images relayed from a microscopemounted video camera to a monitor. This method was validated by manual planimetry in $70 \%$ of the animals, with good correlation between both methods.

Immunohistochemistry. Data on cell kinetics were obtained from immunohistochemistry staining for proliferating cell nuclear antigen (PCNA). This method yields an estimation of the number of cells actively dividing at a given time. ${ }^{13,14}$ Nuclear counting was done with a light microscope at $20 \times$ magnification with a computer-based image analyzer (Optimas). Proliferating cells were defined as those that stained as intensely as central intestinal crypt epithelium at the intimal and medial levels. Cell density was defined as the total number of cells encountered in the intima and the media per millimeter.

Statistical analysis. Mean area and thickness were compared between sections located in the middle of the grafts in group A and sections located immediately after the valve in group B animals, by means of analysis of variance and BMDP software (BMDP Software, Los Angeles, Calif.). The model was specified such that mean area and mean thickness were the dependent variables; the independent variables were presence or absence of valves in the vein grafts and time in weeks from the operation. Contrasts were used to test for differences between groups A and B for each period. Plots of mean area and thickness for the two groups over time were also carried out.

In group B animals, measurements of area and thickness were made at vein cross sections just before and just after the valve. The difference between sections was calculated and tested by a paired $t$ test. Additionally, regression analysis was used to test for trends across evaluation times. Plots of mean and standard error for the difference between areas and thickness proximal and distal to the valves were also performed.

\section{Results}

The highly concentrated cholesterol diet was well tolerated, and serum cholesterol levels rose rapidly to a mean value of $1932 \mathrm{mg} / \mathrm{dl}$ before the animals were killed.

Morphology and immunohistochemistry. Vein grafts implanted in the carotid arterial circulation became progressively thicker as time elapsed and reached a maximum thickness at 8 weeks (Table III). This thickening was due to proliferation of spindle-shaped cells with histologic and immunohistochemical (actin positive) features of smooth muscle cells, as well as a matrix composed of collagen, elastic tissue, and acid mucopolysaccharides. At 2 weeks after implantation of the vein grafts, intimal and medial thickening was associated with an increase in cell number (Fig. 1, $A$ ). At 4 weeks, the number of cells started to decrease, and further increase in thickness was associated with increased extracellular matrix. PCNA expression showed that cell proliferation starts as early as 3 days, remains active at 2 weeks, is only minimal at 4 weeks, and is nonexistent at 6 and 8 weeks (Fig. 1, B).

Fig. 2 shows representative sections of veins at the different times studied. In normal, control veins the media consisted of only a few layers of smooth muscle cells of negligible thickness. By 2 weeks, the media was thickened by a proliferation of tightly packed spindle cells. At 4 weeks, some regions showed less cellularity, with a light pink matrix present. This was also present at 6 weeks when a definite increase in pink collagen was observed within the media. In some cases, after longer durations of implantation, cells with clear abundant cytoplasm (foam cells) were present. These cells had histologic and immunohistochemical features of macrophages. In these veins, extracellular lipid was also observed. 


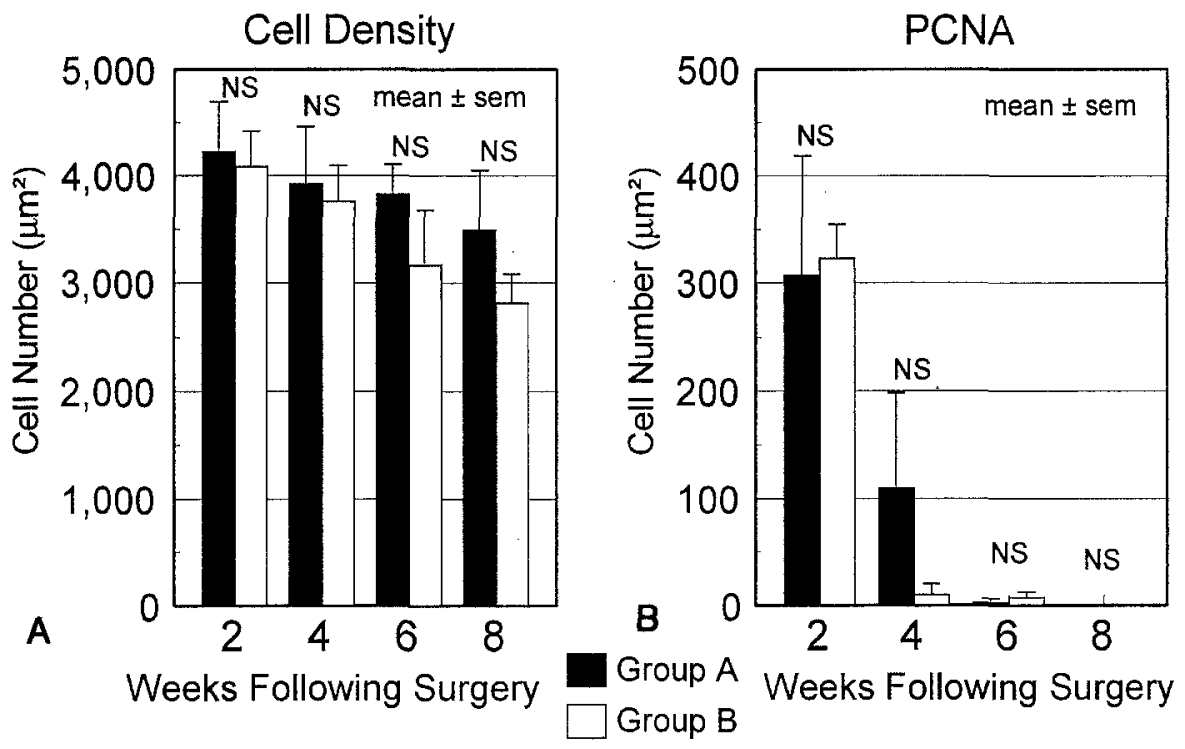

Fig. 1. A, Cell density (number of cells per square micrometer) was largest at 2 weeks and progressively decreased during the time of the experiment. B, PCNA expression reached a maximum at 2 weeks, and it was minimal or nonexistent thereafter. No difference was detected between the two groups.

Fig. 3 shows the changes that were observed in the valves when these were present in the implanted veins. As early as 3 days after implantation, thickening and increased cellularity were observed, most prominent at the base of the valves. Early on, these were primarily spindle cells with features of smooth muscle cells. Later, extracellular matrix was deposited with prominent collagenous tissue present. Foam cells and extracellular lipid were also observed on the valves after longer periods of implantation.

Fig. 4 shows the results of the immunohistochemical studies performed. Within the valves PCNA staining showed prominent cell proliferation as early as 3 days after implantation. This prolifiration decreased with time. On the other hand, vein media away from valves showed most pronounced cell proliferation 2 weeks after implantation. The medial spindle-shaped cells and PCNA-positive cells stained positively for smooth muscle-specific actin, confirming their smooth muscle cell differentiation. The foam cells present stained positively with monoclonal mouse antihuman macrophage, CD68 antiserum. Thus, whereas the early changes consisted primarily of smooth muscle cell proliferation, a common response of the vascular wall to injury, late changes that included macrophages and extracellular lipid deposition were more typical of atheromas.

Morphometry. The changes described herein occurred to a certain degree in both study groups of animals. We made morphometric measurements to quantify these changes and to assess whether there were any differences between the groups, with respect to severity or to the time necessary for the lesions to develop. Analysis of variance for wall thickness or for wall area measurements between segments corresponding to the middle of the graft in group A animals and for segments located immediately after the valve in group B animals (see Table III) failed to show any significant difference at the 2-week period. It was at this time that most of the proliferation of cells, as shown by the expression of PCNA, took place, as well as when the cell density was at the highest level. However, no significant differences between groups A and B in the cell kinetic studies were noted. From this period on, increases in wall thickness and area were greater for group B than group A animals at 4, 6, and 8 weeks. A paired $t$ test, used to identify significant differences between mean wall thickness and area of vein cross sections taken immediately before and after the valve in group B animals (Table IV), showed that measurements were consistently and significantly higher for the sections located after the valve for all time periods, including 2 weeks.

\section{Discussion}

The saphenous vein continues to be an essential component of surgical myocardial revascularization 

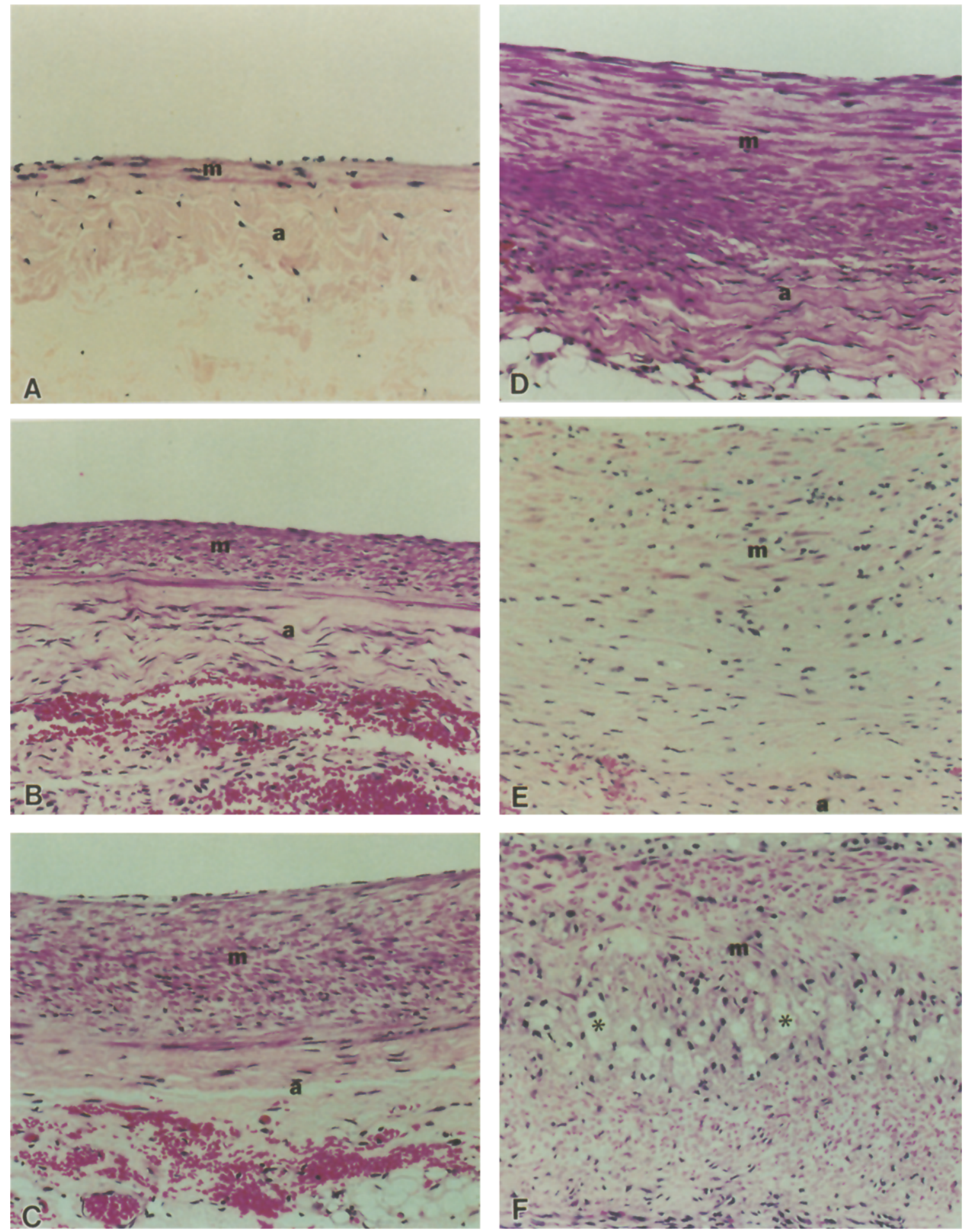

Fig. 2. Media: Photomicrographs at a standard original magnification of $50 \times$ showing progressive increase in medial thickness of veins with time that occurred in both treatment groups. A, Control; B, 2 weeks; C, 4 weeks; $\mathbf{D}, 6$ weeks, $\mathbf{E}$ and $\mathbf{F}, 8$ weeks. Note in $\mathbf{E}$ that at 8 weeks the media was sometimes more fibrous and less cellular and, as shown in $\mathbf{F}$, sometimes contained numerous foamy macrophages (asterisks). $a$, adventitia; $m$, media. (Hematoxylin and eosin stain.) 

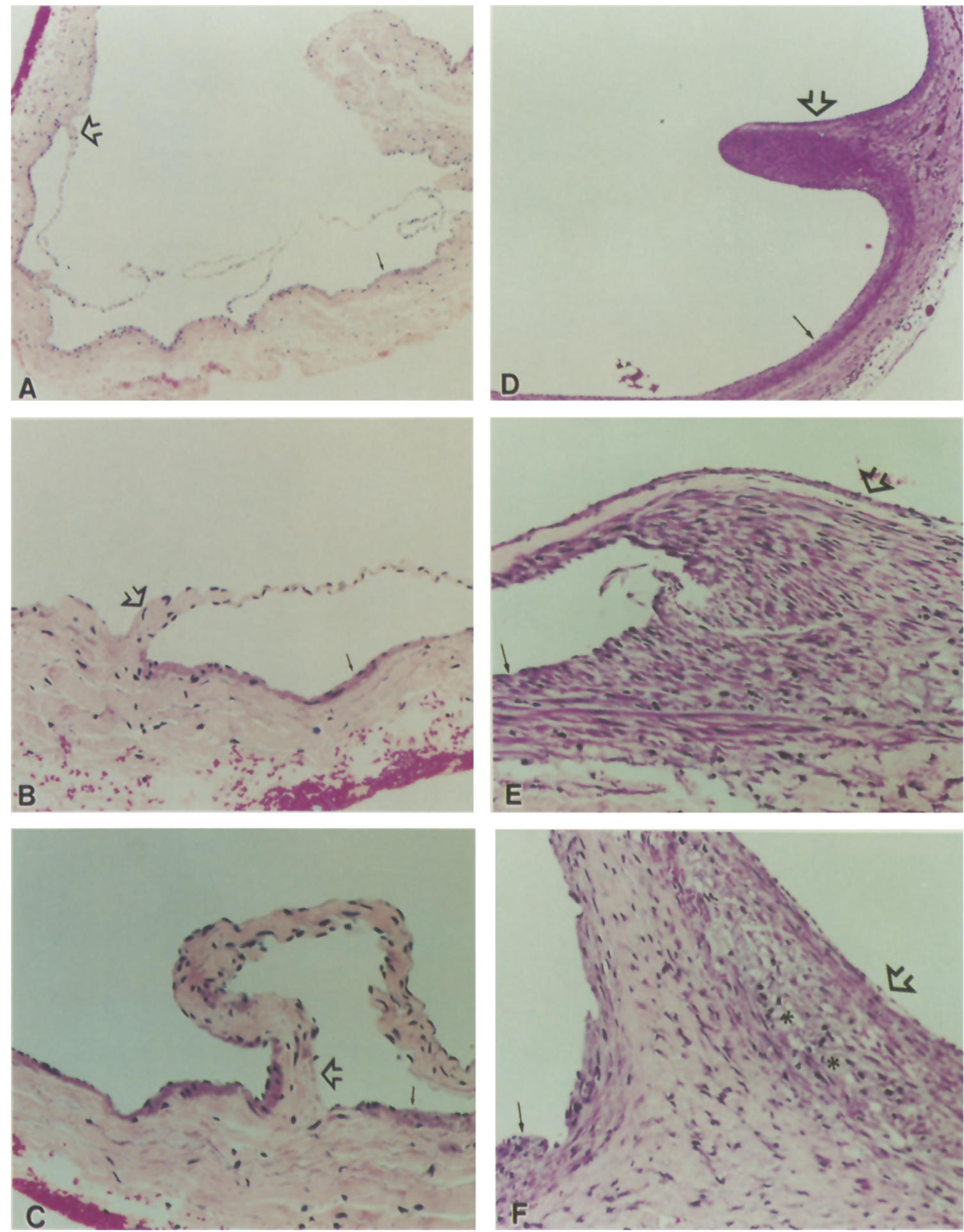

Fig. 3. Valve: Photomicrographs demonstrating venous valvular changes. A, B, and $\mathbf{C}$ are normal valves (open arrows) at $10 \times, 25 \times$, and $50 \times$ magnification; $\mathbf{D}, \mathbf{E}$, and $\mathbf{F}$ are valves from veins implanted for 2 to 6 weeks, shown at $10 \times, 25 \times$, and $50 \times$ magnification. Note the marked thickening of the valve base. In $\mathbf{E}$ this consists primarily of smooth muscle cells. In $\mathbf{F}$ foamy macrophages (asterisks) are also present. D, E, and $\mathbf{F}$ also demonstrate medial proliferation of the adjacent venous wall (small arrows). (Hematoxylin and eosin stain.) 

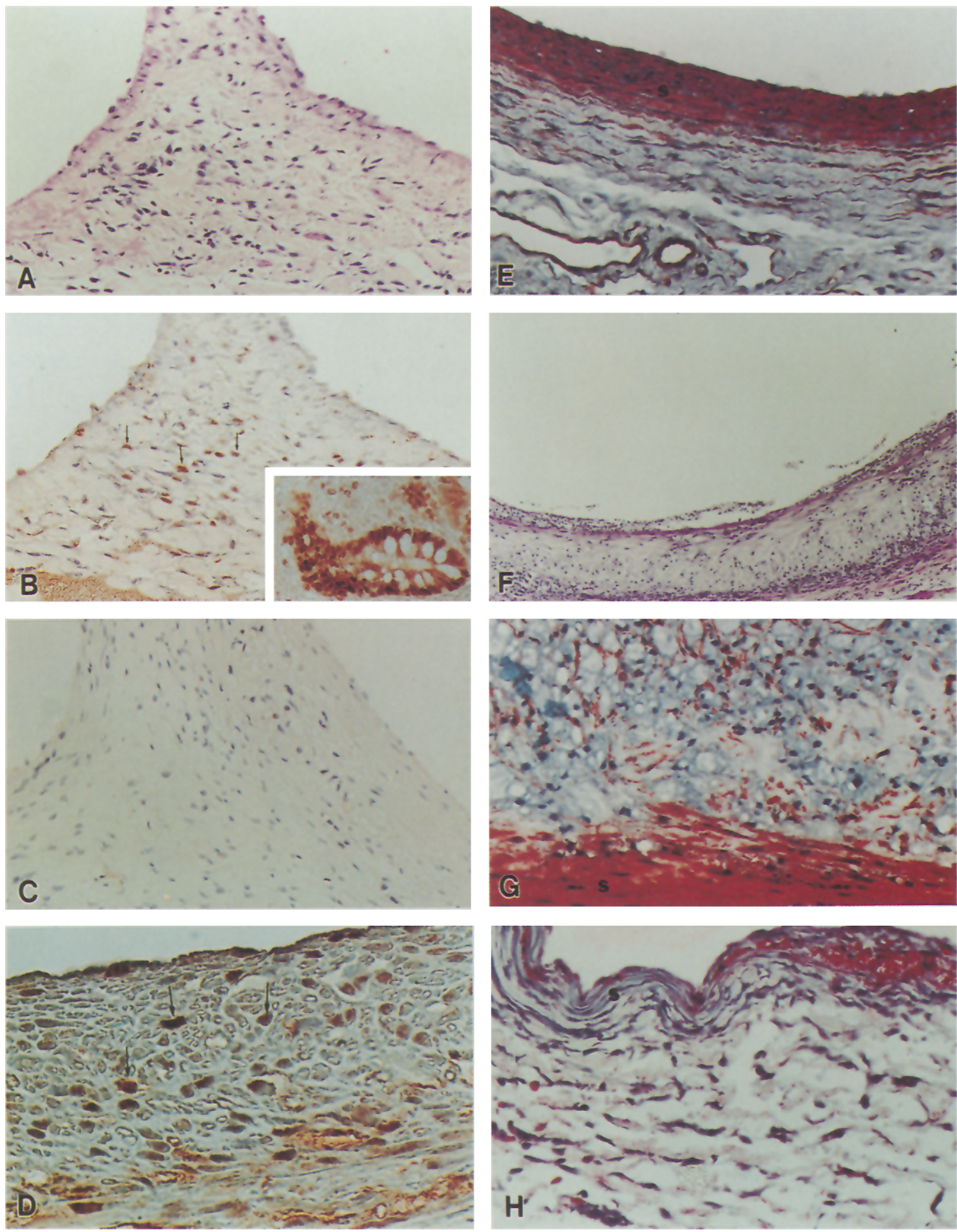

Fig. 4. Immunohistochemistry: Photomicrographs showing results of immunohistochemical studies. A, Hematoxylin and eosin stain of valvular proliferation at 3 days $(50 \times)$. B, PCNA staining showing numerous positive brown-staining cells (arows). Inset shows positive control consisting of intestinal crypt epithelium $(50 \times)$. Adjacent media had little PCNA positivity. C, Valve at 4 weeks showing no PCNA positivity. D, Example of vein wall proliferation of cells (PCNA positivity indicated by arrows) observed within the first 2 weeks after implantation $(100 \times)$. E, An example of staining of the venous wall at 2 weeks for smooth muscle cell(s), specific actin indicating that virtually all the cells are smooth muscle cells $(10 \times)$. F, a vein at 8 weeks, with primarily foam cells in the wall (hematoxylin and eosin stain, $10 \times$ ). G, Most foam cells are negative for smooth muscle-specific actin(s) $(100 \times)$. H, Another vein showing that foam cells stain positively with a macrophage-specific antibody (red), whereas smooth muscle cell(s) fail to stain (100x). 
Table IV. Difference between thickness/area proximal and distal to the vein valve (group $B, n=24$ )

\begin{tabular}{|c|c|c|c|c|c|c|}
\hline & Weeks & No. & $\begin{array}{c}\text { Proximal } \\
\text { (mean) }\end{array}$ & $\begin{array}{r}\text { Distal } \\
\text { (mean) }\end{array}$ & $\begin{array}{c}\text { Difference } \\
(\text { mean } \pm S E M)\end{array}$ & $p$ Value \\
\hline \multicolumn{7}{|l|}{ Thickness $(\mu \mathrm{m})$} \\
\hline & 2 & 6 & 63.0 & 96.5 . & $33.4 \pm 5.4$ & $<0.001$ \\
\hline & 6 & 6 & 147.6 & 183.4 & $35.4 \pm 8.2$ & $<0.008$ \\
\hline & 4 & 6 & 210.1 & 257.3 & $47.2 \pm 3.8$ & \\
\hline & 8 & 6 & 210.5 & 266.5 & $56.0 \pm 14.0$ & $<0.01$ \\
\hline \multicolumn{7}{|l|}{ Area $(\mu \mathrm{m} / \mathrm{mm})$} \\
\hline & 2 & 6 & 61.5 & 95.5 & $34.1 \pm 4.6$ & $<0.001$ \\
\hline & 6 & 6 & 146.3 & 183.4 & $37.1 \pm 6.9$ & $<0.003$ \\
\hline & 4 & 6 & 212.8 & 255.4 & $42.6 \pm 4.4$ & \\
\hline & 8 & 6 & 215.8 & 266.9 & $51.3 \pm 18.5$ & $<0.04$ \\
\hline
\end{tabular}

strategies in human beings. It is the most commonly used conduit, alone or in combination with arterial grafts. Saphenous vein has the advantage of being autologous vascular tissue available in the majority of patients in need of this operation. It has been known for decades that the main limitation of saphenous vein grafts is the propensity for the development of sclerotic changes similar to those seen in the arterial circulation. ${ }^{1}$ In our clinical practice, we have been intrigued by the observation that in patients returning for angiography years after surgery, some grafts are completely occluded or have severe atheromatous changes, whereas others remain perfectly clean and patent. Because these grafts were performed at the same time and have been subjected to presumably similar physiologic and identical metabolic conditions, we have postulated that some intrinsic morphologic characteristics could be different in the segments used for multiple bypasses in the same patient, and that this difference in morphologic features could, at least in part, explain the differences in long-term outcomes. Presence of valves in vein segments has been suspected as being one of the morphologic factors influencing formation of atheromatous lesions. ${ }^{10-12}$

In vitro studies have demonstrated mechanisms by which these valves may influence the hemodynamic flow characteristics of blood through the veins, ${ }^{15-17}$ implicating the valves in the development of proliferative lesions. Noncontrolled animal experiments by Bosher and associates ${ }^{18}$ have suggested that in vivo vein valves could also play a role. The next logical step, then, was to develop an animal model that could either refute or confirm these suspicions in a scientifically controlled manner, as well as allow for future studies. The animal model that we developed differs from previously described New Zealand White rabbit models ${ }^{19}$ in two ways: (1) the presence or absence of vein valves in the segments of internal jugular veins used and (2) the cholesterol concentration in the diet received by the animals and the serum cholesterol levels achieved, which were higher than those previously reported. ${ }^{4}$ This animal model produced changes that developed faster in the wall of the vein graft, thus reducing the duration and cost of the project. These changes were increased proliferation of smooth muscle cells during the first 2 weeks after implantation, and thereafter an increased extracellular matrix formed mainly by mucopolysaccharides and collagen, as well as infiltration of macrophages that later turn into foam cells. If the grafts are left for longer periods, deposits of cholesterol crystals, as well as calcification, can be noted. When wall thickness and area were measured, these morphometric studies confirmed that the changes develop with greater intensity in areas located distal to the vein valves. Our previous in vitro studies, ${ }^{16}$ as well as those performed by Thubrikar, Robicsek, and Fowl$\mathrm{er}^{15}$ and the work by Davies and colleagues, ${ }^{20}$ correlated well with the findings of the present study and suggest that wall tension, increased turbulence, and pressure changes that occur distal to the valves could be responsible for the increased formation of atheromatous lesions in this area. In addition, changes in the diameter of the vein resulting from distention produced by the higher arterial pressure could also be a factor, as suggested by Zweep and coworkers. ${ }^{21}$ The limitations of this animal model as compared with human aorta-coronary saphenous vein bypasses are due to species differences, differences in the structure of the human saphenous vein and the jugular vein of the rabbit, and differences in flow characteristics between the coronary and the carotid circulations.

Despite these limitations, we believe that in hu- 
man beings, careful planning for surgical myocardial revascularization operations can result in the elimination of several veins valves from the segments chosen to bypass the coronary arteries. This, together with optimal management of risk factors after revascularization, ${ }^{22}$ may result in prolonged patency of the venous grafts. Unfortunately, however, when the vein is used to bypass three or more arteries, inevitably some valves will remain in at least some of the segments. For these reasons, and also because all vein grafts will eventually be affected by atheromatous lesions, it is necessary to develop other methods to decrease or eliminate these changes. Attention should be paid not only to the aspects of cell biology and proliferation, but also to the role played by the extracellular matrix. This model or similar ones could be used to test these new methods.

We thank Kathleen Farrington and Michele A. DeRobertis, RN, for their expertise in the preparation of this manuscript.

\section{REFERENCES}

1. Bourassa MG. Fate of venous grafts: the past, the present and future. J Am Coll Cardiol 1991;17:1081-3.

2. Grondin CM, Campeau L, Thornton JC, Engle JC, Cross FS, Schreiber $\mathrm{H}$. Coronary artery bypass grafting with saphenous vein. Circulation 1989;79(Suppl): I24-9.

3. Cox JL, Chiasson DA, Gotlieb AI. Stranger in a strange land: the pathogenesis of saphenous vein graft stenosis with emphasis on structural and functional differences between veins and arteries. Prog Cardiovasc Dis 1991;34:45-68.

4. Zwolak RM, Kirkman TR, Clowes AW. Atherosclerosis in rabbit vein grafts. Arteriosclerosis 1989;9: 374-9.

5. Haimovici $\mathrm{H}$, Maier N. Autogenous vein grafts in experimental canine atherosclerosis. Arch Surg 1974; 109:95-102.

6. Fonkalsrud EW, Sanchez M, Zerubavel R. Morphological evaluation of canine autogenous vein grafts in the arterial circulation. Surgery 1978;84:253-64.

7. Boerboom LE, Olinger GN, Liu T-Z, Rodriguez ER, Ferrans VJ, Kissebah AH. Histologic, morphometric, and biochemical evolution of vein bypass grafts in a nonhuman primate model. I. Sequential changes within the first three months. J THORAC CARDIOVASC SURG 1990;99:97-106.

8. McCann RL, Larson RM, Mitchener JS III, Fuchs JCA, Hagen P. Intimal thickening and hyperlipidemia in experimental primate vascular autografts. Ann Surg 1979;189:62-7.

9. Mills NL, Ochsner JL. Valvulotomy of valves in the saphenous vein graft before coronary artery bypass. $\mathbf{J}$ Thorac Cardiovasc Surg 1976;71:878-9.

10. Takeuchi Y, Suma K. Non-reversed saphenous vein grafting: an improved technique of aortocoronary bypass surgery. J Cardiovasc Surg 1981;22:174-8.

11. Mills NL. Saphenous vein graft valves: "the bad guys." Ann Thorac Surg 1989;48:613-4.

12. Mills JL, Fujitani RM, Taylor SM. The characteristics and anatomic distribution of lesions that cause reversed vein graft failure: a five-year prospective study. J Vase Surg 1993;17:195-206.

13. Garcia RL, Coltrera MD. Analysis of proliferative grade using anti-PCNA/cyclin monoclonal antibodies in fixed, embedded tissues: comparison with flow cytometric analysis. Am J Pathol 1989;134:733-9.

14. Coltrera MD, Gown AM. PCNA/cyclin expression and BrdU uptake define different subpopulations in different cell lines. J Histochem Cytochem 1991;39: 23-30.

15. Thubrikar MJ, Robicsek F, Fowler BL. Pressure trap created by vein valve closure and its role in graft stenosis. J Thorac Cardiovasc Surg 1994;107:70716.

16. Kwack EY, Back LH, Ruan XM, Chaux A. Flow measurements in an aortocoronary bypass graft casting. Adv. Bioeng. 1992;22:325-8.

17. Walsh DB, Downing S, Ahmed SW, Wallace RB. Valvular obstruction of blood through saphenous veins. J Surg Res 1987;42:39-42.

18. Bosher LP, Deck JD, Thubrikar M, Nolan SP. Role of the venous valve in late segmental occlusion of vein grafts. J Surg Res 1979;26:437-46.

19. Murday AJ, Gershlick AH, Syndercombe-Court YD, et al. Intimal hyperplasia in arterial autogenous vein grafts: a new animal model. Cardiovase Res 1983;17: 446-51.

20. Davies PF, Remuzzi A, Gordon EJ, Dewey CF Jr, Gimbrone M Jr. Turbulent fluid shear stress induces vascular endothelial cell turnover in vitro. Proc Natl Acad Sci 1986;83:2114-7.

21. Zweep HP, Satoh S, van der Lei B, Hinrichs WLJ, Feijen J, Wildevuur CRH. Degradation of a supporting prosthesis can optimize arterialization of autologous veins. Ann Thorac Surg 1993;56:1117-22.

22. Pearson T, Rapaport E, Criqui M, et al. Optimal risk factor management in the patient after coronary revascularization: a statement for healthcare professionals from an American Heart Association writing group. Circulation 1994;90:3125-33.

\section{Discussion}

Dr. Mano J. Thubrikar (Charlotte, N.C.). Dr. Robicsek and I have been doing some work with the vein graft, and I congratulate Dr. Chaux and his group for their excellent study.

I have three comments. First, inasmuch as the vein valve is present at the junction of the internal and external 
jugular veins, the diameter of the graft distal to the valve is likely to be larger than that proximally. Consequently, the thickness and the wall area are likely to be greater distally. Couldn't this produce different degrees of hyperplasia?

Second, comparing valveless grafts with valved grafts gives the impression that increased atherosclerotic changes develop in the entire vein graft, whereas in fact the proximal segment of the valved graft shows changes similar to those in the graft without the valve. This distinction is important.

Third point: The question should be not only whether the valve is present in the graft but whether the valve is functional. For instance, as is shown in this slide, on the angiogram the valve was closed on the left and open on the right, and down below ultrasonic images of the vein valve show closed and open positions of the valve.

When the vein graft is put in the arterial system we begin to understand why nature did not put valves in the artery. When the mean graft flow decreases, the valve cyclically opens and closes much like the aortic valve, and suddenly there is a pressure trap distal to the valve just as there is a separation of aortic and ventricular pressures. Thus the closed valve traps the pressure distally, which means it produces a diastolic hypertension. But also, the flow trace has a character of the aortic flow, which means there is a zero flow period during each cardiac cycle. Thus, if the valve is functional, then there is a distal hypertension and a stagnation of flow. When the valve is not functional, there is still turbulence behind the leaflets. The graft thus may exhibit different characteristics depending on whether the valve is functional or not.

In general, I agree with the conclusion that the valve is likely to exacerbate atherosclerotic changes. To me the important question is not only whether the valve is there but whether the valve is functional.

Dr. Chaux. Thank you for your comments. Let me go back to your first question: Yes, there is a difference in diameter of the vein, given the presence of a valve at the division of the internal jugular vein. This occurs in human beings, as well. Frequently there is a difference in the diameter of the saphenous vein proximal and distal to a valve, and that is one of the reasons that we chose to use this model and try to mimic as much as possible the conditions in the human coronary grafts. We think that the difference in diameter is important in the pathogenesis of the lesions.

With respect to the second issue that you raised, I think you are correct. However, this is a hypercholesterolemic rabbit model. Eventually arteriosclerotic changes will develop in the vascular systems of all these rabbits.

With respect to your comments regarding the function of the valve, I am familiar with your work, and I think that what you have suggested is a possible mechanism for the development of these lesions, but there are other possible mechanisms as well.

Dr. Thomas Z. Lajos (Buffalo, N.Y.). These findings are strongly supported by our clinical observations in the past 12 years.

We have used the side-to-side aorta-saphenous graft since 1970. The valveless limb of the "horseshoe graft" has been depicted since 1983, with a 12-year long-term followup. We have used a valveless segment and a valvular segment in the same patient. We have a follow-up on 78 patients and 306 grafts. There is a trend toward increased overall patency of $78.4 \%$ in the valveless limb versus $72.5 \%$ in the limb with valves in 12 years' follow-up. Comparing the sequential valvular and valveless limbs, there is a significant increase in the patency of the sequential valveless segment, $88 \%$ versus $70.2 \%(p<$ 0.05 ) in 12 years. Patency of the valveless limb is also significantly increased if this valveless segment is directed to the left side $(81.5 \%$ vs $67.8 \%, p<0.05)$.

I think our data show that the valveless vein segment has a higher patency in long-term follow-up then the "average" reversed saphenous vein with the valves.

Dr. Chaux. Thank you very much. We have similar clinical observations, and they motivated us to perform these experiments in the laboratory and to come up with some answers. 